\section{$\underset{\substack{\text { hommes } \\ \text { \& migrations }}}{ }$}

\section{Hommes \& migrations}

Revue française de référence sur les dynamiques

migratoires

$1324 \mid 2019$

Religion et discrimination

\title{
Relever le défi des discriminations
}

\section{Marie Poinsot}

\section{CpenEdition \\ Journals}

\section{Édition électronique}

URL : https://journals.openedition.org/hommesmigrations/8145

DOI : 10.4000/hommesmigrations.8145

ISSN : 2262-3353

\section{Éditeur}

Musée national de l'histoire de l'immigration

\section{Édition imprimée}

Date de publication : 1 janvier 2019

Pagination : 3

ISBN : 978-2-919040-44-5

ISSN : $1142-852 X$

\section{Référence électronique}

Marie Poinsot, «Relever le défi des discriminations », Hommes \& migrations [En ligne], 1324 | 2019, mis en ligne le 01 janvier 2019, consulté le 08 janvier 2022. URL : http://journals.openedition.org/ hommesmigrations/8145; DOI : https://doi.org/10.4000/hommesmigrations.8145 


\section{Édito}

\section{Relever le défi des discriminations}

\section{Marie Poinsot,}

rédactrice en chef de la revue. la veille du Brexit et des élections européennes qui risquent de dévoiler l'ampleur des nationalismes fondés sur le refus des migrations et « la haine de l'impur », pour reprendre un titre de Carolin Emcke, ce numéro d'Hommes \& Migrations alimente la démarche de sensibilisation et de débat citoyen que développe le Musée national de l'histoire de l'immigration sur les discriminations. Pour cette raison, il paraît en préparation du Grand Festival qui déploie fin mars 2019 au musée une programmation pluridisciplinaire pendant la Semaine d'éducation et d'actions contre le racisme, l'antisémitisme et les discriminations, en partenariat avec la Délégation interministérielle à la lutte contre le racisme, l'antisémitisme et la haine anti-LGBT (Dilcrah).

Hommes \& Migrations a été l'une des premières revues françaises à faire paraître, dès les années 1990, plusieurs dossiers thématiques sur les discriminations plurielles. Dans un dossier sur le tournant médiatique de l'année 1983 (n 1313, janvier-mars 2016), la revue montrait combien les stéréotypes initiaux de l'« Arabe » avaient imprégné l'imaginaire social en une multitude de préjugés sur les populations originaires du Maghreb. Avec la montée d'une lecture sécuritaire des migrations et la diffusion de l'idée de préférence nationale dans l'opinion, les débats politico-médiatiques vont prendre pour cible, au fil des décennies, la figure des musulmans. Parler de la relation entre religion et migration interroge presque exclusivement la place de l'islam dans la société.

Hommes \& Migrations diffuse aujourd'hui de nouveaux chantiers de la recherche sur ce thème. Coordonné par Patrick Simon et Liza Rives, ce numéro aborde la question des discriminations sous l'angle de l'assignation à une religion. L'appartenance religieuse au sens large est-elle devenue un des facteurs principaux de marginalisation et de rejet des populations musulmanes en France ? L'étude des discriminations en France menée par l'Institut national d'études démo- graphiques (Ined) dans le cadre de l'enquête Trajectoires et origines interroge les religions et leurs représentations complexes dans l'espace public, postulant que ces problématiques sociales sont d'abord construites dans l'épaisseur des processus historiques propres à chaque société (colonisation, décolonisation, migrations postcoloniales pour la France). Si le terme d'« islamophobie » contient une forte charge polémique, il est utilement discuté ici pour qualifier, au-delà des discriminations qui visent les musulmans et leur religion, un processus de racialisation structurant de manière permanente les préjugés et les attitudes négatives, voire hostiles, qui s'exercent à l'encontre de ces populations en vertu d'un faisceau de facteurs interconnectés (l'appartenance raciale, les croyances et pratiques religieuses, les cultures, les situations sociales et économiques, l'identité générationnelle, etc.). Plusieurs articles concluent en effet à la consolidation d'un racisme antimusulman dans les sociétés civiles et les sphères politicomédiatiques, sous des formes différentes selon les contextes géographiques. Ils comparent des situations nationales entre elles (la France, les États-Unis, la Grande-Bretagne et la Belgique) pour détailler les variations de nature et d'échelle des discriminations, toujours à la croisée du racisme, du sexisme, de l'âgisme et d'autres stéréotypes. Rappelons que ces discriminations créent des situations d'injustices matérielles et de domination réelle ou symbolique des populations musulmanes. L'analyse des politiques de lutte contre les discriminations souligne la politisation croissante du cadre de la laïcité qui a tendance à agir comme un levier sur la visibilité de l'islam, sur le sentiment d'être discriminé par les services publics, et favorise une gestion paradoxale des problématiques religieuses par les collectivités territoriales et par les entreprises.

Les deux autres parties du numéro sont consacrées aux activités du musée et à l'actualité culturelle au prisme des représentations tronquées ou occultées des migrations. C'est la mission que la revue continue d'assurer pour relever le défi des discriminations. 